University of Nebraska - Lincoln

DigitalCommons@University of Nebraska - Lincoln

Mechanical \& Materials Engineering Faculty

Publications

Mechanical \& Materials Engineering,

Department of

2012

\title{
Sacrificial Structure Preforms for Thin Part Machining
}

Scott Smith

Robert Wilhelm

Brian Dutterer

Harish Cherukuri

Gaurav Goel

Follow this and additional works at: https://digitalcommons.unl.edu/mechengfacpub

Part of the Mechanics of Materials Commons, Nanoscience and Nanotechnology Commons, Other Engineering Science and Materials Commons, and the Other Mechanical Engineering Commons

This Article is brought to you for free and open access by the Mechanical \& Materials Engineering, Department of at DigitalCommons@University of Nebraska - Lincoln. It has been accepted for inclusion in Mechanical \& Materials Engineering Faculty Publications by an authorized administrator of DigitalCommons@University of Nebraska Lincoln. 
Published in CIRP Annals - Manufacturing Technology 61:1 (2012), pp. 379-382;

doi: 10.1016/j.cirp.2012.03.142

Copyright (C) 2012 CIRP; published by Elsevier. Used by permission.

Published online April 30, 2012.

\title{
Sacrificial Structure Preforms for Thin Part Machining
}

\author{
Scott Smith, Robert Wilhelm, Brian Dutterer, Harish Cherukuri, \\ and Gaurav Goel
}

Department of Mechanical Engineering, University of North Carolina at Charlotte, Charlotte, North Carolina, USA

Corresponding author - Scott Smith, email kssmith@uncc.edu

\begin{abstract}
Thin parts are often difficult to create by machining because they have insufficient static and dynamic stiffness. Accurate thin parts are difficult to achieve due to clamping forces, cutting forces, residual stresses, and chatter. Sacrificial structure preforms support the part during machining, but they are not part of the finished component. Preforms may be created in many ways, including forging, welding, gluing, casting, or additive processes. They can be used in many workpiece materials including metals, polymers, and ceramics. We describe a novel process that uses sacrificial structures to make machining insensitive to the thinness of finished parts.
\end{abstract}

Keywords: machining, structure, sacrificial

\section{Introduction}

In many application areas, such as aerospace, it is desirable to have thin metallic structures. The machining of such thin components as monolithic structures has largely replaced sheet metal assembly operations for aluminum components, as shown for the avionics tray in Figure 1. The thin aluminum machining strategy described in [1-3] begins with a stressrelieved plate stock workpiece, and the machining progresses layer by layer using relieved shank tooling as shown in Figure 2. The workpiece is machined where it is stiff, and the 
thin sections are left behind. The workpiece derives its stiffness from the not-yet-machined stock, a substantial portion of which can be seen in Figure 2.

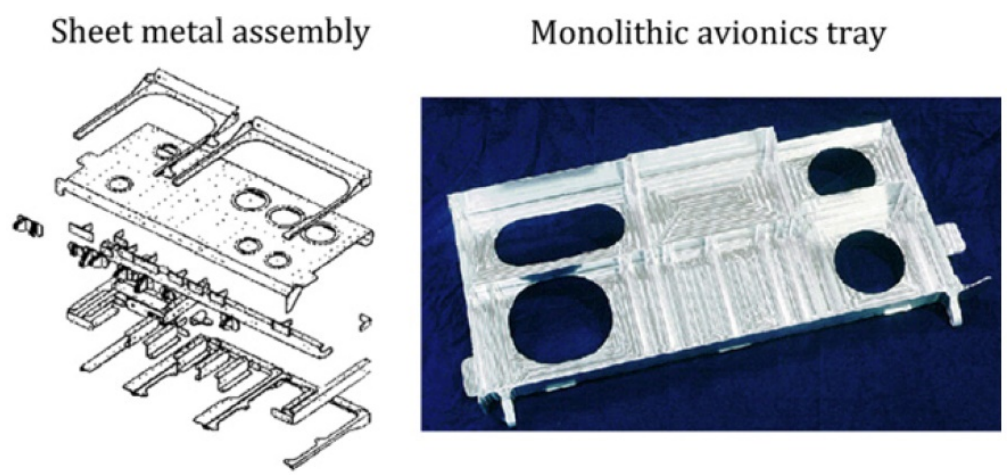

Figure 1. Thin machined monolithic aluminum avionics tray (right) replaces a 44-part sheet metal assembly (left).
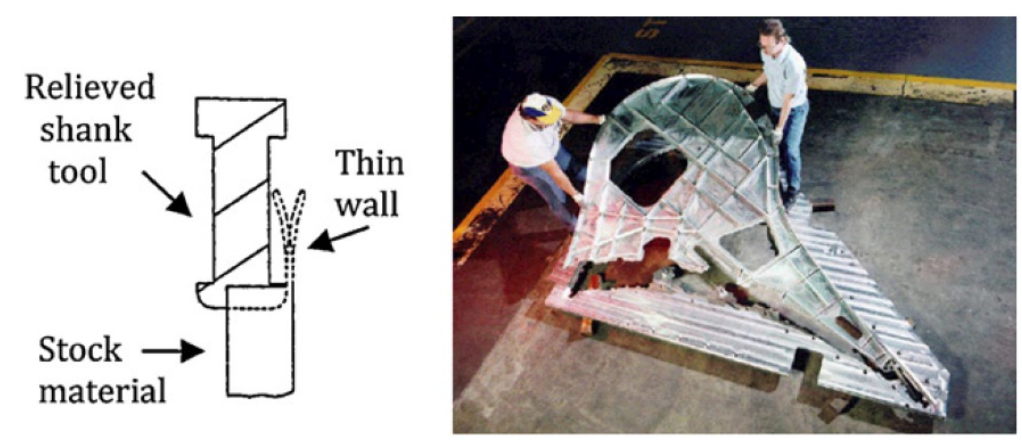

Figure 2. Relieved shank tooling and monolithic machining strategy.

The reduction in assembly cost and the improvement in precision have been enormous, and monolithic aluminum parts are now widespread in the aerospace industry [4].

Unfortunately, this strategy has not proven as useful for difficult-to-machine materials such as titanium or nickel alloys, for several reasons:

- The processes required to produce the desired material properties are not compatible with stress-relieved plate stock, as in aluminum.

- The workpiece material is so far too expensive to start from a solid block.

- Tool wear requirements demand small radial depths of cut (restricting contact time and lowering maximum temperature) during milling.

Many researchers have attempted to make thin components in difficult materials using near net shape forming [5], additive processes [6], and near net shape casting [7]. The preforms made using such techniques still need machining to reach the final geometry, but 
they are already so thin that they make stable accurate machining difficult [8]. Some researchers have resorted to innovative fixturing techniques [9] to hold these thin workpieces during machining.

In this paper, we describe a novel machining process that uses sacrificial structures to make the machining insensitive to the thinness of finished parts. In the following sections, the approach is first described conceptually and the attributes needed for useful sacrificial structures are outlined. A simple example is presented with both FEA analysis and machining results to illustrate the process and show typical results. A more involved example is then presented to demonstrate how this process extends to larger complex parts. The conclusions summarize current techniques that we have defined for this process and include a discussion of interesting new research directions to extend this work further.

\section{Sacrificial structures in machining preforms}

The goal of this research is to enable high precision machining of thin features in tough and expensive materials at high efficiency and low cost. To arrive at a suitable solution, we define a machining process that uses preform geometries that reduce material usage while offering stiffness during machining and minimizing tool wear effects. For the class of complex thin-walled parts that we have studied, the following three attributes of successful preform geometries have been identified:

1. The sacrificial structure preform geometry must completely contain the shape of the finished part while seeking to minimize the workpiece material consumption.

2. The preform with sacrificial structural stiffeners should increase the minimum stiffness of the preform so that it is higher than that of the finished part by an order of magnitude or more.

3. The sacrificial structures of the preform must be constructed and positioned to efficiently support expected machining forces while minimizing tool wear associated with the eventual removal of the sacrificial structure.

The sacrificial structures described support the workpiece during machining but are not functionally part of the finished workpiece. They may be in the form of buttresses, corrugations, ribs, flanges, and many other geometries. The total mass of the preforms created this way can be substantially less than the plate stock or the thick near-net shapes required for stable machining.

\section{Sacrificial preform examples}

As an example, Figure 3 shows a 7050-T7 aluminum wall that is $60 \mathrm{~mm}$ tall, $100 \mathrm{~mm}$ wide, and $7 \mathrm{~mm}$ thick. This coupon represents a conventional near-net-shape straight wall preform for a finished wall $1 \mathrm{~mm}$ thick. Starting with the preform, machining was performed using a $12 \mathrm{~mm}$ diameter 2-flute solid carbide end mill at 17,000 rpm. The tool has a relieved shank, a $40^{\circ}$ helix, and a $0.76 \mathrm{~mm}$ corner radius. In plate stock, this tool could make a $3 \mathrm{~mm}$ deep slot at this speed without chatter. The tool was used to make a small cut at the top of 
the wall $3 \mathrm{~mm}$ deep but only $1 \mathrm{~mm}$ wide at 17,000 rpm. As the zoomed inset shows, this cut was already unstable because of insufficient stiffness of the preform wall.

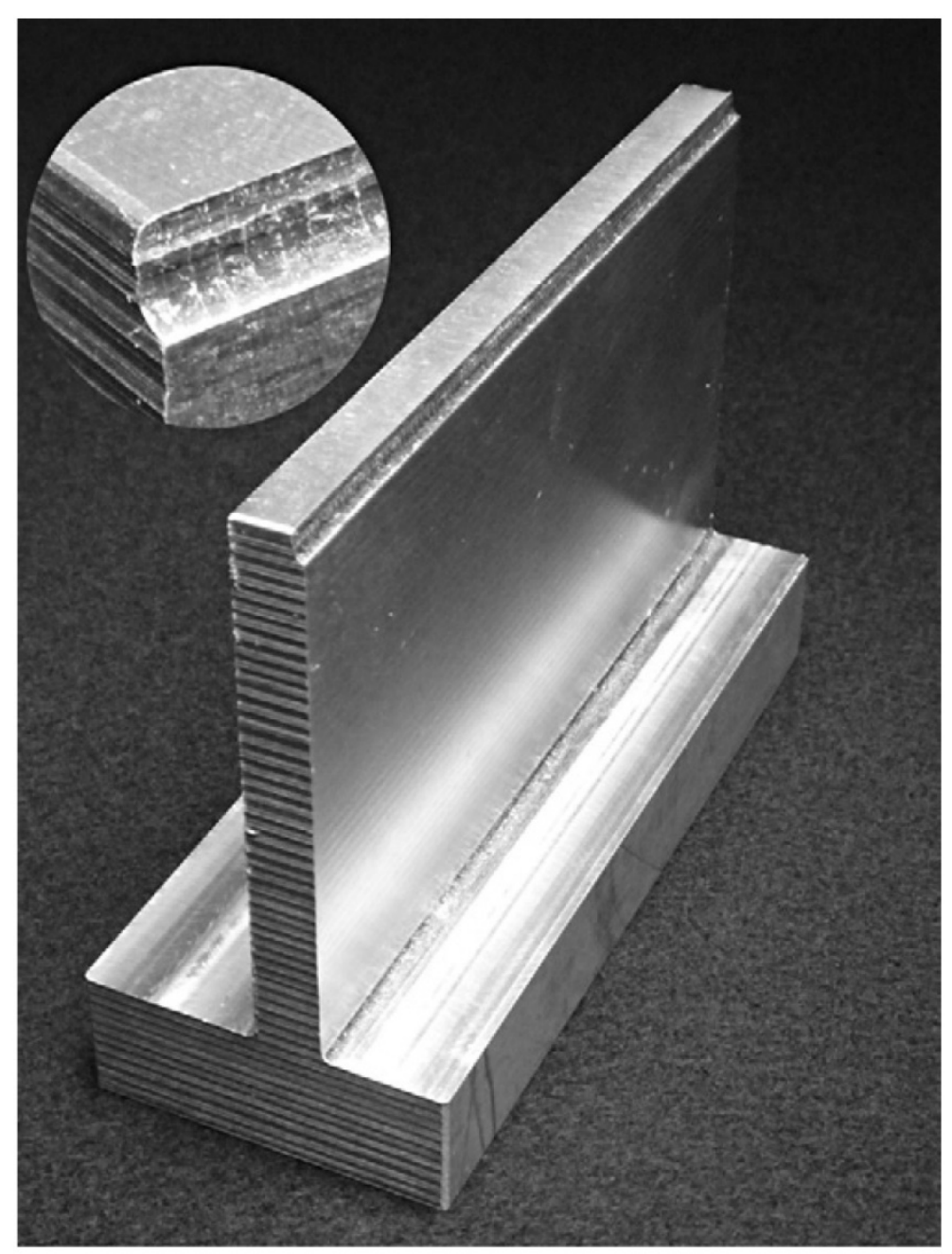

Figure 3. Straight wall preform with chatter (inset).

One approach to prevent the chatter shown in Figure 3 would be to add stiffness by simply increasing the thickness of the preform wall. This approach satisfies the 2nd required attribute we identified in Section 2 but fails on attributes 1 and 3. We have generated a number of different alternative preform geometries to evaluate their performance according to our three process design attributes.

We next used finite element analysis to estimate structural stiffness for each of the candidate preform coupons and to evaluate the ability of each preform to support anticipated machining forces. Figure 4 shows the $2.6 \mathrm{~mm}$ thick straight wall preform (a), a preform of the same thickness with buttresses on one side (b), a preform with buttresses on both sides 
(c), a sinusoidal corrugation preform with a long wavelength (d), and a sinusoidal preform with a short wavelength (e). While other geometries are also possible, this selection of geometries is illustrative. Each of these preforms contains the desired $1 \mathrm{~mm}$ thick finished wall. As will be demonstrated for this example coupon, the preforms with buttresses best satisfy the three process design attributes.

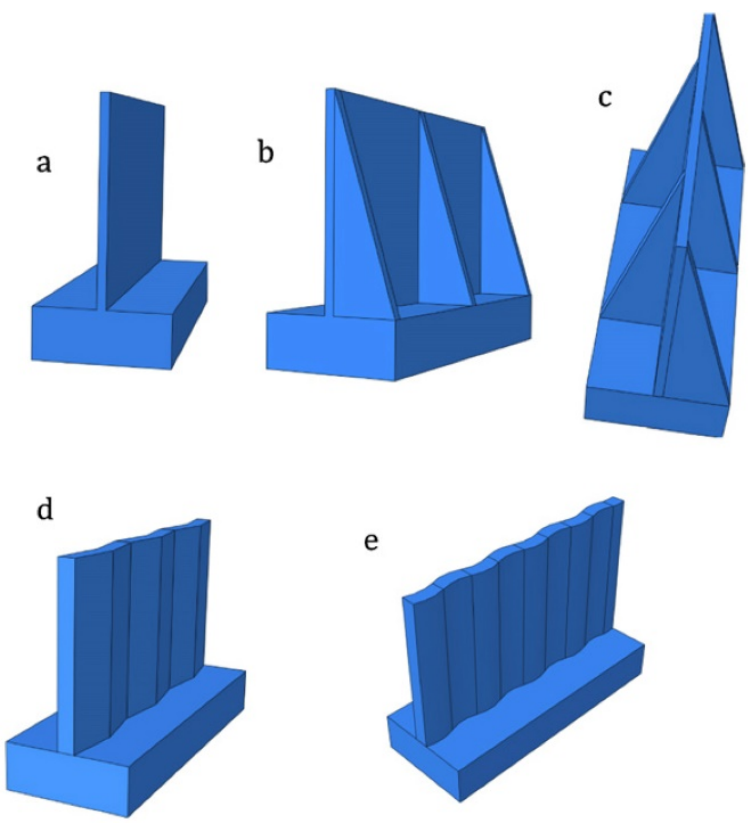

Figure 4. Sacrificial structure preform coupons in buttressed and corrugated geometries.

The stiffness of each of the coupons was calculated due to a point force applied at various points along the top edge, normal to the finished wall. The calculations were performed using the finite element software ABAQUS. Each of the coupon models was discretized using 8-node brick elements with reduced integration.

In each case, the mesh used was sufficiently fine to assure an accurate solution. The displacement at the point of application of the force in the direction of the force was obtained for each case using static, linear elastic analysis. The stiffness was calculated as the ratio of the applied force and this displacement. An example displacement result is shown in Figure 5. 


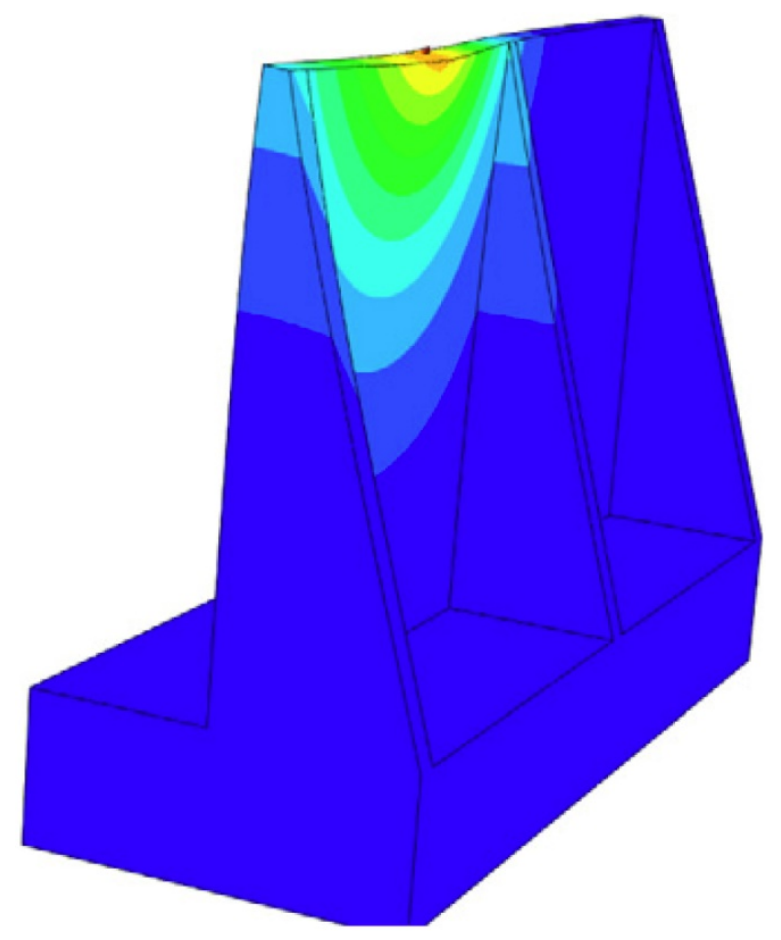

Figure 5. Finite element calculation of deflection due to a force applied at the top edge of the preform.

The applied force was moved along the top of the wall to find the lowest stiffness for each case, and the results are shown in Table 1. The case lettering corresponds to that shown in Figure 4. In addition the volume of the preform above the base is shown for each case.

\begin{tabular}{ccc}
\hline \multicolumn{3}{c}{ Table 1. FEA computed minimum stiffness of the preforms shown in Figure 4} \\
\hline Case & Minimum stiffness $(\mathrm{N} / \mathrm{m})$ & Volume $\left(\mathrm{cm}^{3}\right)$ \\
\hline $\mathrm{a}$ & $0.69 \times 10^{5}$ & 14.67 \\
$\mathrm{~b}$ & $5.03 \times 10^{5}$ & 18.61 \\
$\mathrm{c}$ & $5.33 \times 10^{5}$ & 21.23 \\
$\mathrm{~d}$ & $4.0 \times 10^{5}$ & 28.14 \\
$\mathrm{e}$ & $3.90 \times 10^{5}$ & 30.55 \\
\hline
\end{tabular}

Machining tests on the coupons showed that the preforms with buttresses, cases $\mathrm{b}$ and c, provided ample stiffness for stable machining at 17,000 rpm, $3 \mathrm{~mm}$ axial depth of cut, and $1 \mathrm{~mm}$ radial depth of cut, while cases a, $\mathrm{d}$, and e did not. From this, it can be inferred that the required minimum stiffness for stable machining at these conditions was between the $4.0 \times 10^{5} \mathrm{~N} / \mathrm{m}$ of case $\mathrm{d}$ and $5.03 \times 10^{5} \mathrm{~N} / \mathrm{m}$ of case $\mathrm{b}$. 
Further calculation showed that the straight wall preform of case a would have to be increased in thickness to $6.1 \mathrm{~mm}$ in order to provide the minimum stiffness for stable machining, and the resulting volume would be $34.34 \mathrm{~cm}^{3}$. Each of the example cases b-e generally reduced overall material in the preform compared to this standard. Qualitatively, cases b and c, with a small number of very thin buttresses to remove, reduce tool wear due to removal of sacrificial structures. The overall material volume of each case provides an even more compelling metric. The successful cases required between $18.6 \mathrm{~cm}^{3}$ and $21.2 \mathrm{~cm}^{3}$ of preform material while unsuccessful cases 4 and 5 required between 28.1 and $30.6 \mathrm{~cm}^{3}$ of preform material. Choosing a preform with buttresses on one side allows stable machining of the finished geometry from a preform with approximately $46 \%$ of the volume of the near net shape straight wall preform.

\section{Extension to larger structures}

Applying the three attributes for preform geometries and using the results from finite element computations, a preform was created for a large pan as shown in Figure 6. The preform is on the left and the finished part is on the right. In the finished part, the walls are 60 $\mathrm{mm}$ tall. The floors and walls are all $1 \mathrm{~mm}$ thick, and the overall pan width is $480 \mathrm{~mm}$. In the preform, the walls, buttresses, and ribs are $2.6 \mathrm{~mm}$ thick. Ribs on the floor play the same role for the floor as the buttresses play for the thin walls. The preform was clamped to the table of the machine tool using toe clamps at the 4 corners of the preform. Although the preform was made by milling, it simulates a preform created by any other process. It can be seen from the finished part on the right that all of the machining was stable. The total machining time for this part was less than 10 min. Figure 7 shows a detail of the stiffening ribs. Figure 8 shows a close-up photograph of the finished part (front) and the preform (back). The now nonfunctional remnants of the buttresses can be seen next to the channel that was used to separate the finished workpiece. Figure 9 shows an alternate configuration of the floor ribs, and the resulting finished part. The large pan case studies demonstrate that our approach can be applied successfully to complex thin-walled parts of considerable scale. In earlier studies, large pans of this scale were fabricated from monolithic material from which more than $90 \%$ of the material volume was removed to achieve the finished part. The cases shown here avoid almost all of this excess material while providing the work piece stiffness required to precisely machine thin-walled pans. 


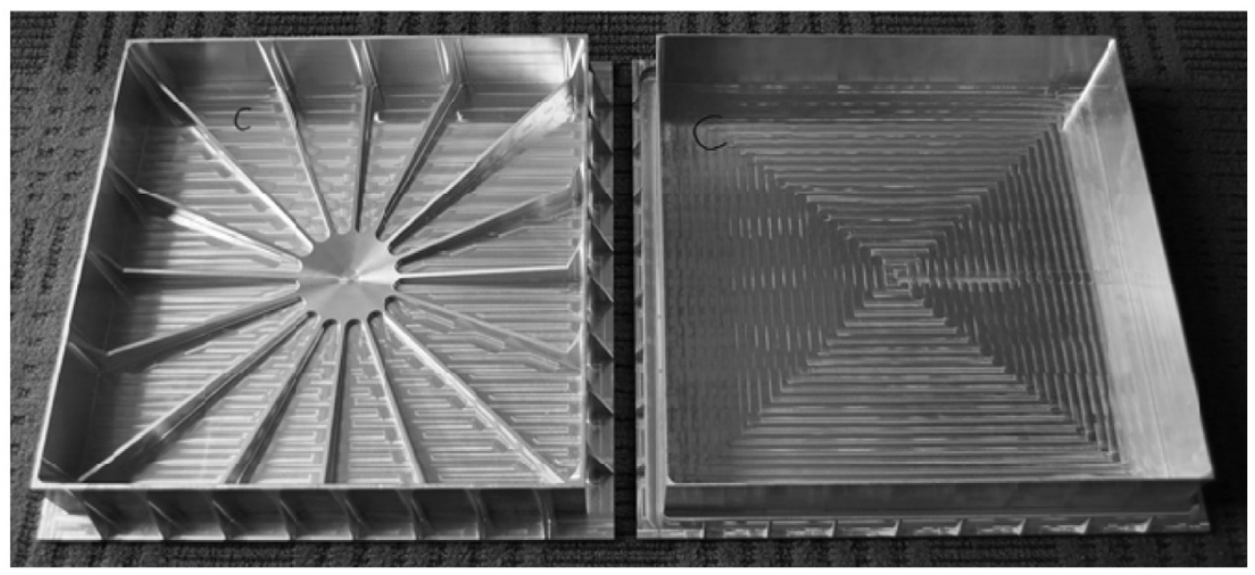

Figure 6. Pan preform with floor ribs and buttresses (left) and finished part with thin walls and thin floor (right).

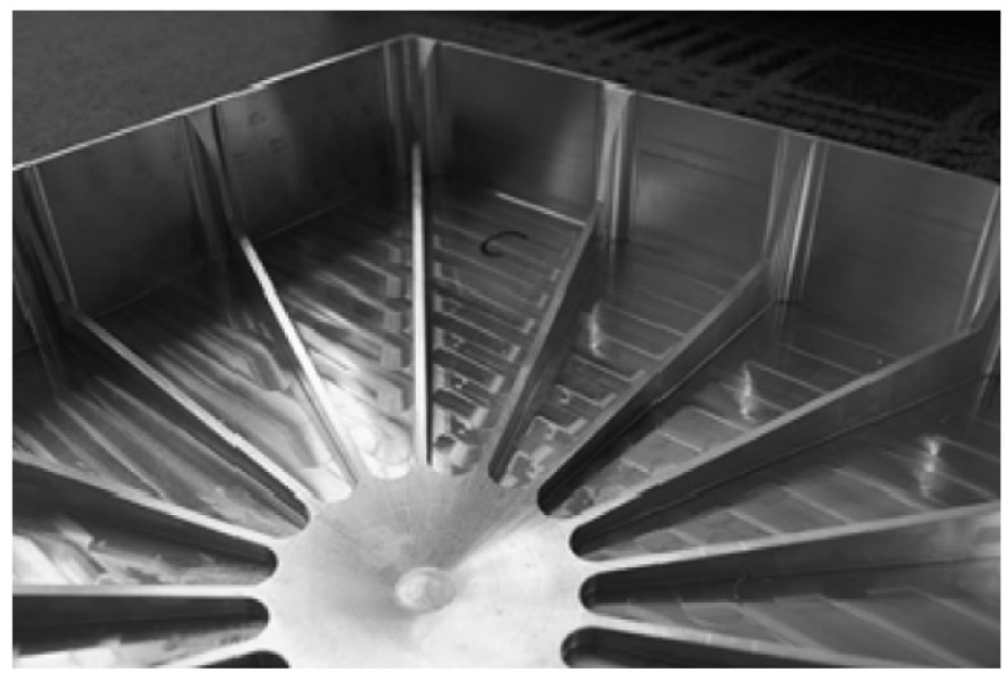

Figure 7. Detail of the floor stiffening ribs and wall buttresses in the pan preform. 


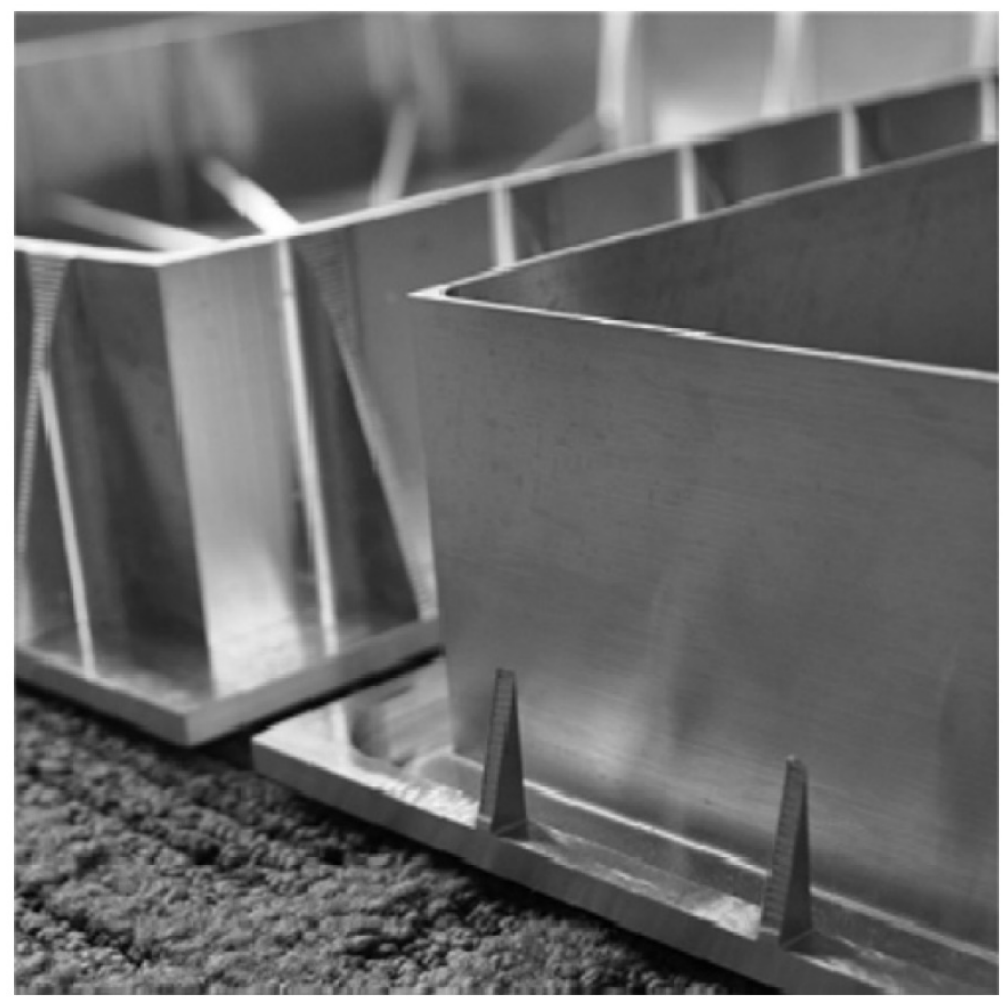

Figure 8. Stiffening buttress remnants during machining of the part in Figure 6, with another preform visible in the background.

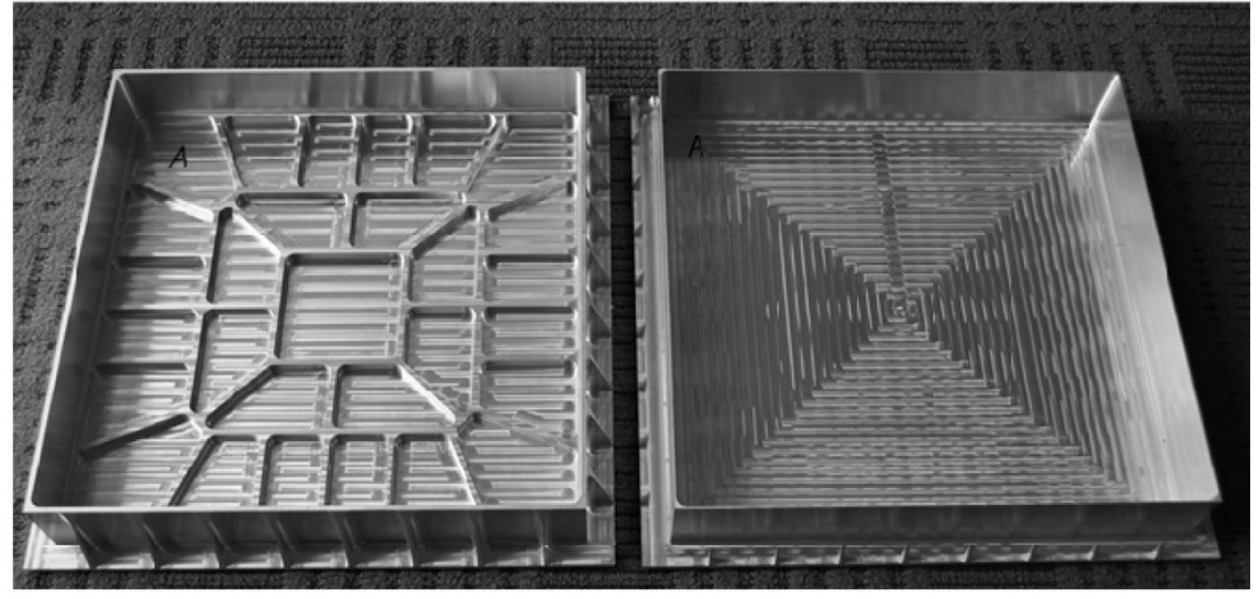

Figure 9. Alternate pan preform with stiffeners and buttresses (left) and finished thin part (right). 


\section{Conclusions}

Sacrificial structure preforms allow stable, accurate machining of thin components in difficult materials, from preforms with small initial volumes. Preforms with sacrificial structure can be designed to reduce overall workpiece material consumption while simultaneously providing sufficient stiffness for required machining and minimizing tool wear. The general preform design procedure is:

- Start with finished part

- Add minimum thickness to allow for finish machining

- Estimate the stiffness of the finished part

- Add sacrificial stiffeners to increase minimum stiffness by an order of magnitude or more

The example part demonstrated the concept, showing significantly reduced material volume in the preform, a machining strategy compatible with low tool wear in difficult materials and an efficient machining time. This technique forms the basis of a more general approach with at least the following open problems:

- Generally selecting combinations of cutting conditions and work piece stiffnesses and geometries

- Identification of additional satisfying attributes for specific applications

- Selection and optimization of preforms as a function of preform fabrication methods.

\section{References}

[1] Tlusty J, et al, (1996) Techniques for the Use of Long Slender End Mills in Highspeed Milling. Annals of the CIRP 45(1):393-396.

[2] Smith S, et al, (1998) The Effect of Tool Length on Stable Metal Removal Rate in High Speed Milling. Annals of the CIRP 47(1):307-310.

[3] Smith S, Dvorak D (1998) Tool Path Strategies for High Speed Milling Aluminum Workpieces with Thin Webs. Mechatronics Journal 8(3):291-300.

[4] Halley J, et al, (1999) The Impact of High Speed Machining of Aluminum on the Design and Configuration of Aerospace Components. Proceedings of the 1999 ASME Design Engineering Technical Conference, $1-5$.

[5] Altan T, Miller R (1990) Design for Forming and Other Nearnet Shaping Process. Annals of the CIRP 39(2):609-620.

[6] Kruth J (1998) Progress in Additive Manufacturing and Rapid Prototyping. Annals of the CIRP 47(2):525-540.

[7] Lee D, et al, (2003) Thin Wall Titanium Structural Castings. Advanced Materials and Processes 161(5):21-24.

[8] Arnaud L, et al, (2011) Simulation of Low Rigidity Part Machining Applied to Thin-walled Structures. International Journal of Advanced Manufacturing Technology 54:479-488.

[9] Aoyama T, Kakinuma Y (2005) Development of Fixture Devices for Thin and Compliant Workpieces. Annals of the CIRP 54(1):325-328. 